\title{
STUDI EKSEGETIS TENTANG KEKUATIRAN MENURUT MATIUS 6:25-34
}

Waharman

waharman@sttab.ac.id

Abstract: In this article, discuss the words of the Lord Jesus about worries according to Matthew 6: 25-34. The purpose of the Lord Jesus was to advise His disciples so that they would not worry about food, drink and clothing. These words are a motivation for believers in God in matters of food and drink, so that believers are free from all worries and entrust themselves to God in His pets. While still alive in this world, Jesus gave guidelines for living in His care and He also emphasized to His disciples that they first seek the kingdom of God and His truth and all of that will be added to you (Matt. 6:33). Here Jesus does not promise that all believers will become wealthy, but promises the providence of God that meets all the needs of His children, even the glory and riches of heaven. Jesus even used the parable of the birds that were fed by the Father in heaven. If God feeds them, He will also take care of His people. In this article it reminds Christians not only to be concerned about worries, but must surrender fully to God and live in God's care, grateful for God's blessings in an extraordinary way.

Keywords: Exegetical Study, worry.

\begin{abstract}
Abstrak: Dalam artikel ini, membahas tentang perkataan Tuhan Yesus tentang kekuatiran menurut Matius 6:25-34. Maksud Tuhan Yesus menasehatkan para murid-murid-Nya supaya mereka tidak kuatir tentang makanan, minuman dan pakaian. Perkataan ini merupakan suatu motivasi bagi orang percaya kepada Allah dalam hal makanan dan minuman, sehingga orang percaya terlepas dari segala kekhawatiran dan mempercayakan diri kepada Allah dalam peliharaan-Nya. Selama masih hidup di dunia ini, Yesus memberikan pedoman untuk hidup dalam pemeliharaan-Nya dan Ia juga menegaskan kepada murid-murid-Nya supaya mereka mencari dahulu kerajaan Allah dan kebenaran-Nya maka semuanya itu akan ditambahkan kepadamu (Mat. 6:33).Di sini Yesus tidak menjanjikan bahwa semua orang percaya akan menjadi kaya raya, tetapi menjanjikan pemeliharaan Allah yang mencukupi semua kebutuhan anak-anak-Nya, bahkan kemuliaan dan kekayaan surgawi. Bahkan Yesus menggunakan perumpamaan mengenai burung-burung yang diberi makan oleh Bapa di surga. Kalau Allah memberi mereka makan, maka Ia juga akan memelihara umat-Nya. Dalam artikel ini mengingatkan kepada orang Kristen supaya tidak hanya dimengerti tentang kekuatiran, tetapi harus menyerahkan diri sepenuhnya kepada Tuhan dan hidup dalam pemeliharaan Tuhan, mensyukuri berkat-berkat Tuhan secara luar biasa.
\end{abstract}

Kata Kunci: Studi Eksegetis, kekuatiran. 


\section{LATAR BELAKANG}

Kekuatiran merupakan perasaan yang mungkin melumpuhkan diri manusia atau jiwanya yang benar-benar lumpuh karena kekuatirannya. Dengan terjemahan lain, kuatir merupakan dari dua kata berarti berpikir, sedangkan yang lain membagi atau mendua hati. Ini berarti kekuatiran dapat menyebabkan pikiran kita terbelah dua. ${ }^{1}$ Karena kekuatiran itu begitu akrab dengan kita, maka mungkin saja kita sulit untuk mendefenisikan secara tepat kebiasaan yang menyusahkan diri kita sendiri. Misalnya dalam pergumulan kita persis sama seperti yang dialami oleh para ahli dengan membedakan antara kekuatiran dengan kecemasan, ketakutan, kepanikan, keprihatinan atau kekuatiran dengan perencanaan yang masuk akal. $^{2}$

Berdasarkan paparan di atas dapat disimpulkan bahwa defenisi kekuatiran ini merupakan kelumpuhan jiwa seseorang atau membagi pikiran berarti mendua hati dan ia merasakan kecemasan, kepanikan, ketakutan yang masuk akal.

Kekuatiran dianggap sebagai masalah serius, karena ini bisa menimpa orang-orang percaya dengan mengakibatkan atau menghancurkan kehidupan iman kita, dengan arti kurang percaya akan pemeliharaan Tuhan. ${ }^{3}$ Karena kekuatiran mungkin menuduh Tuhan sebagai pembohong. Karena Tuhan berjanji akan memenuhi segala kebutuhan kita (Fil. 4:19). Karena kebutuhan ini merupakan salah satu yang kita kuatirkan dalam kehidupan kita yang terus-menerus sehingga kekuatiran itu merupakan penyangkalan diri kita dan ketidakpercayaan kita secara terang-terangan bahwa Allah tidak mampu atau tidak ingin menepati janji-Nya kepada kita. Selanjutnya kekuatiran menghancurkan hubungan kita dengan Tuhan dan membuat kita bertanya-tanya apakah Tuhan Allah benar-benar akan menyertai kita pada saat kita membutuhkan-Nya. ${ }^{4}$

\footnotetext{
${ }^{1}$ David T. Moore, Kuatir Pedoman Bagi Konselor..., 26

${ }^{2}$ Ibid..., 34

${ }^{3}$ Karel Sosipater, Etika Perjanjian Baru,(Jakarta : Suara harapan Bangsa, 2010), 216

${ }^{4}$ David T. Moore, Kuatir Pedoman Bagi Konselor..., 65
} 
Berdasarkan paparan di atas kuatir berarti kurang mempercayaiakan pemeliharaan Tuhan atau menuduh Tuhan sebagai pembohong sehingga ia menyangkal janji pemeliharan Tuhan (Fil.4:19).

\section{Akibat dari Kekuatiran}

Dampak dari kekuatiran dalam terjemahan bahasa Yunani "merimnao" secara harafiah berarti melenceng ke arah lain artinya mengkhawatirkan hal-hal materi sama saja hidupnya yang tidak mengenal Allah atau tidak mengutamakan kerajaan Allah (Mat.6:33). ${ }^{5}$ Clarinda mengatakan kekhawatiran adalah membunuh, yaitu membunuh firman Tuhan yang ada dalam diri kita. Seperti yang telah dikatakan oleh Tuhan Yesus dalam perumpamaan tersebut bahwa kekhwatiran dapat menghimpit dan membunuh roh kita. Dengan kata lain, kekhawatiran memiliki kesanggupan untuk menyumbat jalan napas, mencekik, dan membuat nyawa roh kita mati lemas. ${ }^{6}$

Berdasarkan paparan di atas kekuatiran berarti melenceng ke arah yang lain atau meninggalkan Tuhan karena selalu memikirkan materi dan Clarinda mengatakan akibat dari kekuatiran itu sama halnya membunuh roh dan susah bernafas.

\section{Eksegese Teks Matius 6:25-34}

Pada bagian ini akan membahas makna ungkapan Tuhan Yesus Tentang Kekuatiran Matius 6:25-34. Matius ingin menjelaskan nasehat Tuhan Yesus tentang kekuatiran terkhusus kepada murid-murid-Nya. Supaya para pengikutNya bebas dari kekuatiran tentang makanan, minuman dan pakaian, itulah maksud Matius agar orang percaya saat ini hidup dalam pemeliharaan Tuhan.

Penulis Injil Matius, adalah Matius, yaitu salah satu dari kedua belas murid Tuhan Yesus. ${ }^{7}$ Stamps menyatakan bahwa tempat Injil Matius adalah

\footnotetext{
${ }^{5}$ Warren W. Wiersbe, Loyal Di dalam Kristus Mengikut Raja segala Raja, (Bandung: Yayasan Kalam Hidup, 2012), 69

${ }^{6}$ Regina Clarinda, You Are a Survivor, (Yogyakarta: Majalah Rohani, 2011), 56

${ }^{7}$ Marulak Pasaribu, Eksposisi Injil Sinoptik Mengenal Yesus Yang Diberitakan Dalam Injil Sinoptik, (Malang: Gandum Mas, 2005), 135
} 
"ketika berada di Palestina atau antiokhia di Siria". Injil Matius ini ditulis antara tahun 60-65, beberapa beberapa penafsir yang dilakukan oleh para teolog yang kebanyakan menyimpulkan kalau Injil ini ditulis antara tahun 70M. Tujuannya untuk memberikan kesaksian kisah kehidupan Yesus dan untuk meyakinkan bahwa Yesus adalah Anak Allah dan Mesias, seperti yang dinubuatkan oleh nabinabi Perjanjian Lama. ${ }^{9}$ Nixon menjelaskan bahwa Injil Matius bertujuan untuk mengajar mereka "orang Yahudi” dengan teliti dan cermat bagaimana Yesus telah menggenapi nubuat-nubuat PL dan telah meletakkan dasar-dasar bagi gereja, sebagaimana gereja adalah penerusan umat Allah dari PL tetapi telah dipebaharui sehingga bukan lagi berdasarkan keturunan melainkan berdasarkan kerohanian yang terdiri dari orang-orang atas segala bangsa sehingga dimaksudkan bagi para pembaca akan sanggup menangkis serangan-serangan orang Yahudi atau orangorang yang non Kristen. ${ }^{10}$

\section{Eksegese Ungkapan "Janganlah Kuatir" 6:25-34}

Dalam bagian ini akan mengexegese beberapa kata penting untuk mendapatkan kajian yang mendalam sehingga dapat memahami makna ungkapan Tuhan Yesus tentng kekuatiran. Ungakapan "Janganlah kuatir" dalam bahasa Yunani dibagi menjadi dua kata yaitu "janganlah" dan” kuatir”. Kata janganlah dalam bahasa Yunani memakai $\mu \eta$ (me) artinya tidak, jangan, supaya jangan, apakah, mungkin, jangan lagi. ${ }^{11}$ Sedangkan kata kuatir dalam bahasa Yunani memakai $\mu \varepsilon \rho \mu \nu \alpha ́ \tau \varepsilon$ (merimnate) berasal dari kata $\mu \varepsilon \rho \mu \nu \alpha ́ \omega ~(m e r i m n a o)$ artinya merasa khawatir, memperhatikan. Kata ini memakai kasus verb imperative present active middle orang kedua jamak (kata kerja yang sedang terjadi terus menerus yang dilakukan oleh banyak orang. Secara harafiah janganlah kuatir pada ayat 25 ini merupakan kata perintah yang harus dilakukan oleh seseorang

${ }^{8}$ Donald C. Stamps, Alkitab Penuntun Hidup berkelimpahan, (Malang: Gandum Mas, 2006), 1495

${ }^{9}$ Monny, Selalu Ingat Membaca Alkitab,(Jakarta : Sinondang Media, 2006), 87

${ }^{10}$ Nixon, R.E, Dalam Tafsiran Masa Kini Jilid 3 (Jakarta : OMF, 2006), 63

11 Hasan Sutanto, Perjanjian Baru Interlinear Yunani Indonesia dan Konkordansi Perjanjian Baru (PBIK) Jilid I, (Jakarta : Lembaga Alkitab Indonesia, 2006), 517 
terus menerus dalam kehidupannya sehari-hari. Pada ayat ini Tuhan Yesus memerintahkan semua orang agar tidak kuatir dalam segala apapun.

Dalam Kamus Besar Bahasa Indonesia khawatir takut sesuatu yang belum terjadi; merasa gelisah, cemas. ${ }^{12}$ Niw International Version a sense of uneasiness and anxiety about the future, artinya suatu perasaan atau rasa gelisah masa depan. $^{13}$ Dalam ayat 25, Yesus mengidentifikasikan tiga sumber utama kekuatiran yang dihadapi oleh para pengikut-Nya. Sumber pertama makanan, minuman dan pakaian. Makanan merupakan urusan yang serius bagi masyarakat zaman itu. ${ }^{14}$ Stamps mengatakan Yesus tidak bermaksud mengadakan persiapan untuk kebutuhan fisik di masa depan adalah salah. Yang dilarang oleh Yesus adalah kekuatiran atau kecemasan yang menunjukkan bahwa kita kurang percaya akan pemeliharaan dan kasih Allah sebagai Bapa kita (1Pet. 5:7). ${ }^{15}$ Sebaliknya, Beck berpendapat bahwa orang yang bebas dari kekuatiran adalah orang yang diberkati oleh Tuhan karena ia selalu memusatkan perhatiaannya terus-menerus kepada Tuhan dan mengimani pemeliharaan Tuhan. ${ }^{16}$ Itulah tujuan Yesus kepada murid-murid-Nya dengan motivasi yang tunggal dan utama dalam setiap pribadi orang Kristen supaya mereka mencari dahulu kerajaan Allah dan kebenarannya (Mat. 6:33). ${ }^{17}$

Berdasarkan paparan di atas penulis menyimpulkan arti janganlah kuatir berarti agar jangan ada rasa takut dan gelisah, cemas, karena kekuatiran tidak menolong manusia masa depan. Hal ini sesuai yang dikatakan Stamp bahwa kekuatiran adalah karena kurang percaya atau kurang iman.

\section{Cara mengatasi Kekuatiran}

\footnotetext{
${ }^{12}$ Daniel Haryono, (Jakarta: PT Muliapurna Jayaterbit, 2012), 441

${ }^{13}$ E. Alister Mcgrath, The Niv Thematic Study Bible (Holdder \& Stoughton: London Sydey Auckland, 1996), 1921

${ }^{14}$ David T. Moore, Kuatir Pedoman Bagi Konselor, (Jakarta: BPk Gunung Mulia, 2011), 157

${ }^{15}$ Donald C. Stamps, Alkitab Penuntun Hidup berkelimpahan, (Malang: Gandum Mas, 2006), 1510

16 James R. Beck, Bimbingan Praktis mengatasi Kekuatiran, (Jakarta: BPK Gunung Mulia, 2001), 20

17 Jimmy Rungkat, Theologi Politik Yesus, (Batu Malang: Depatermen Literatur Multimedia, (2010), 95
} 
Nasehat hidup janganlah kuatir, sebenarnya sudah berulang-ulang disampaikan dari PL dan PB. Misalanya dalam PL, Salomo menjelaskan bahwa kesedihan adalah kekuatiran dalam hati diri manusia. Jadi, kesedihan merupakan beban kecemasan yang sudah terjadi dalam diri manusia sedangkan ketakutan adalah tidak berani atau membuatnya tidak mampu mengarahkan tenaga untuk melakukan apa yang harus dilakukan, atau mengumpulkan kekuatan untuk menanggung apa yang harus ditanggung (Ams. 12:25). ${ }^{18}$ Ternyata dalam PB Tuhan Yesus menjelaskan bahwa sering manusia kuatir tentang makanan dan minuman. Kekuatiran dapat menjadi berlebihan, dan dapat menjadi semacam penyakit. Ia mengatakan kepada pengikut-pengikut-Nya "Janganlah kuatir akan hidupmu" bukankah hidup lebih penting daripada makanan dan minuman. Arti perkataan-perkataan itu ialah bahwa Tuhan yang telah berbuat hal yang besar. ${ }^{19}$ Rasul Petrus menjelaskan bahwa janganlah kalian merasa khawatir mengenai segala sesuatu. Biarkan Allah mengurus kebutuhan kalian, maksud dari pernyataan Petrus ini ialah pemeliharaan Tuhan (1Pet. 5:7). ${ }^{20}$

“Janganlah kuatir akan hidupmu”. Perkataan ini merupakan suatu motivasi bagi orang percaya kepada Allah dalam hal makanan dan minuman, sehingga orang percaya terlepas dari segala kekhawatiran dan mempercayakan diri kepada Allah dalam pemeliharaan-Nya. Maksud dari perkataan Tuhan Yesus ini supaya orang percaya tidak akan kuatir dalam hal apa pun baik makanan dan minuman.

Ternyata kekuatiran bukan hanya soal makanan dan minuman, tetapi dapat mempengaruhi kesehatan dan tidak bisa tidur. Heer mengatakan:

"Para ilmu jiwa tahu tentang kekuatiran dapat menekankan jiwa berjuta-juta orang, akibatnya orang tidak bisa tidur, sehingga kekuatiran kadang-kadang disebut "penyakit utama" dan "musuh utama untuk kaum manusia". Dengan kekuatiran dan kegelisahan, kehidupan manusia tidak dapat

\footnotetext{
${ }^{18}$ Matthew Henry, Kitab Amsal (Surabaya: Momentum Christian Literature, 2013), 252

${ }^{19}$ J.J. de Heer, Injil Matius (Jakarta: Gunung Mulia, 2011), 113

${ }^{20}$ Daniel C. Arichea, Surat Pertama Petrus,(Jakarta : Lembaga Alkitab Indonesia, 2013), 172
} 
diperpanjang, sebaliknya menurut ilmu kedokteran modern, memakan kesehatan dan memperpendek umur manusia". ${ }^{21}$

Wang menjelaskan bahwa hasil laporan kedokteran menemukan $80 \%$ potensi penyakit manusia adalah ketegangan atau stres, kegelisahan, ketakutan dan kekhawatiran kesehatan seseorang yang sangat ditentukan oleh kondisi pikiran manusia. Pikiran yang negatif membuat orang lebih mudah tertekan penyakit. $^{22}$ Sedangkan Martasudjita menjelaskan bahwa zaman sekarang ini, rasanya tidak ada orang yang terbebas dari rasa khawatir. Khawatir akan masa depan, khawatir akan kesehatan, khawatir tidak punya uang untuk makan, khawatir tidak punya uang sekolah anak, khawatir apakah anak-anak terlibat dalam obat-obat yang terlarang dan pergaulan bebas. ${ }^{23}$

Selanjutnya dalam pandangan Alkitab Tuhan Yesus memberikan nasehat kepada pengikut-Nya supaya mereka tidak lepas dari kebahagiaan dan penyertaan Tuhan. Tong menjelaskan:

"Janganlah kuatir akan hidupmu" orang yang tidak kuatir menikmati hidup yang jauh lebih bahagia daripada mereka yang penuh kekuatiran. Orang yang tidak kuatir menikmati kuasa iman, sukacita dan penyertaan Tuhan". ${ }^{24}$

Henry mengatakan bahwa Tuhan Yesus memberikan nasehat dan perintah agar kita jangan khawatir tentang hal-hal didunia ini. Misalnya makanan, minuman, pakaian, sakit penyakit atau masalah jodoh. ${ }^{25}$ Jika kita simak pernyataan Barclay mengenai kekhawatiran itu tidak perlu, tidak berguna, bahkan merusak hubungan kita dengan Allah. ${ }^{26}$

\footnotetext{
${ }^{21}$ J.J. de Heer, Injil...,113

22 Andri Wang, Rahasia Tiongkok Kuno Untuk Sehat Bahagia dan Panjang Umur,(Jakarta :PT Gramedia Pustaka utama. Anggota IKAPI, 2011), 61

${ }^{23}$ E. Martasudjita, Inspirasi Batin Renungan Sepanjang Tahun 1,(Yogyakarta : Kanisus anggota IKAPI), 351

${ }^{24}$ Stephen Tong, Pengudusan emosi,(Surabaya : Momentum Christian Literature, 2007), 143.

${ }^{25}$ Matthew Henry, Injil Matius 1-14,( Surabaya: Momentum Christian Literature, 2014), 267

${ }^{26}$ William Barclay, Pemahaman Alkitab setiap hari Injil Matius 1-10, (Jakarta : Gunung Mulia, 2003), 423
} 
Henry menjelaskan karena hidup kita merupakan berkat yang lebih besar. Memang benar bahwa hidup tidak dapat bertahan tanpa nafkah, tetapi makanan, minuman dan pakaian yang dipandang tidak lebih tinggi nilainya daripada hidup dan tubuh itu sendiri hanya merupakan hiasan dan kesenangan saja. ${ }^{27}$

Orang yang hidup di dalam Tuhan dengan tekun meyakinkan penyertaan Tuhan dan pemeliharaan-Nya. Drewes mengatakan bahwa:

"Nats-nats ini muncul dalam rangka peringatan Yesus supaya jangan kita kuatir akan hal makan, minuman dan pakaian. Allah tahu bahwa kita membutuhkan hal-hal itu. Kita disuruh untuk memprioritaskan mencari kerajaan Allah dan dalam nats ini kata dikaiosune ditambahkan untuk menjelaskan istilah kerajaan. Kata Yunani dikaiosune ini dapat diterjemahkan dengan "kebenaran" dan "keadilan". Maka kiranya jelas bahwa "carilah dahulu kerajaan Allah dan kebenaran/keadilan Dia" tidak berarti bahwa manusia harus mencari dua hal, melainkan satu hal, yaitu perwujudan pemerintahan Allah didunia ini. $^{28}$

Terkait hal ini di atas, menjelaskan bahwa seorang pengikut Kristus seharusnya memprioritaskan mencari dahulu kerajaan Allah dan kebenaran-Nya (Mat. 6:33-34). Selain itu, Antony menjelaskan bahwa selama hidup di dunia ini, Yesus memberikan pedoman untuk hidup dalam pemeliharaan Tuhan, yaitu "carilah dahulu kerajaan Allah dan kebenaran-Nya maka semuanya akan ditambahkan kepadamu" (Mat. 6:33). Di sini Yesus tidak menjanjikan bahwa semua orang percaya akan menjadi kaya raya, tetapi menjanjikan pemeliharaan Allah yang mencukupi semua kebutuhan anak-anak-Nya, bahkan kemuliaan dan kekayaan surgawi. ${ }^{29}$ Yesus menggunakan perumpamaan mengenai burungburung yang diberi makan oleh Bapa di surga. Kalau Allah memberi mereka makan, maka Ia juga akan memelihara umat-Nya. ${ }^{30}$

Arichea menjelaskan sebab Ia memelihara orang percaya yang mencari dahulu kerajaan Allah dan keadilan-Nya. Istilah pemeliharaan menggunakan

\footnotetext{
${ }^{27}$ Ibid.., 270

${ }^{28}$ Drewes, SatuInjil Tiga Pekabar, (Jakarta : Gunung Mulia, 2012), 208.

${ }^{29}$ Yan Antony, Teologi Prjanjian Baru ,(Bandung : Kalam Hidup, 2014), 91

${ }^{30}$ John F. Walvoord, pedoman Lengkap Nubuat Alkitab, (yayasan kalam Hidup, 2003), 475
} 
kata kerja berarti memperhatikan sesuatu, membimbing, menjaga atau melindungi. Dalam konteks ini, memelihara berarti bersikap peduli terhadap keadaan buruk yang dialami oleh orang percaya. ${ }^{31}$

Stine menjelaskan bahwa "janganlah kuatir akan hidupmu”, misalnya janganlah terlalu merisaukan atau janganlah membiarkan kekhawatiranmu terlalu mengganggumu. ${ }^{32}$ Barclay menjelaskan bahwa kekhawatiran hanya ada pada diri orang yang belum mengenal Allah. Karena kekhawatiran pada dasarnya adalah ketidak percayaan kepada Allah. ${ }^{33}$ Sedangkan Brill mengatakan orang yang merasa khawatir bertentangan dengan Tuhan Yesus atau tidak percaya akan pemeliharaan Allah. ${ }^{34}$

Sosipater mengatakan bahwa Tuhan Yesus tidak melarang seseorang untuk memikirkan dan mempersiapkan kebutuhan akan hari esok (2 Kor. 12:13; 1 Tim 5:8). Namun janganlah kekuatiran itu membelenggu hidupnya, yang akibatnya dapat melumpuhkan kehidupannya dan kerohaniannya. ${ }^{35}$ Akibat dari kekuatiran dalam bahasa Yunani menggunakan kata zeteo artinya ditarik kearah yang berlainan atau meninggalkan pemeliraan Tuhan. Dengan tujuan membawa kearah yang berlawanan dengan iman dari sudut kerohanian sehingga kekuatiran merupakan pencuri sukacita yang besar. ${ }^{36}$

Bargent mengatakan bahwa perkataan Tuhan Yesus mengenai kekwatiran dalam ayat 25-34 (Luk.12:22-34) merupakan usaha untuk membebaskan para pengikut-Nya dari kekhawatiran yang berlebihan mengenai makanan, minuman dan pakaian. Mereka didorong untuk mengingat pemeliharaan Allah seperti yang dinampakkan dalam alam (burung-burung dan bunga bakung) dan untuk

${ }^{31}$ Daniel C. Arichea, Surat Pertama Petrus, (Jakarta : Lembaga Alkitab Indonesia, 2013), 173

${ }^{32}$ Philip C. Stine, Injil Matius, (Jakarta : Lembaga Alkitab Indonesia, 2008), 172.

${ }^{33}$ William Barclay, Injil Matius 1-10, (Jakarta : BPK Gunung Mulia, 2003), 421.

${ }^{34}$ Wesley Brill, Tafsiran Surat Filipi, (Bandung : Yayasan Kalam Hidup, 2003), 118

${ }^{35}$ Karel Sosipater, Etika Perjanjan Baru, (Jakarta: Suara Harapan Bangsa, 2010), 216

${ }^{36}$ Warren W, Wiersbe, Sukacita Di Dalam Kristus, (Bandung : Yayasan Kalam Hidup, 1999), 121 
menyadari bahwa manusia lebih penting dari pandangan Allah. Mereka diminta untuk mengakui bahwa kekhwatiran tidak memberi jalan keluar apa-apa. ${ }^{37}$

Pernyataan Allah ini menunjukkan kepada pengikut-Nya, supaya mereka menjauhkan diri dari kekuatiran yang menakutkan masa depan. Henry mengatakan bahwa:

"Ketamakan ini adalah kekhawatiran mengenai kebutuhan-kebutuhan hidup: janganlah kekhawatiranmu, entah khawatir memikirkan bagaiamana kamu melindungi hidupmu, ketika dalam bahaya, atau khawatir memikirkan bagaimana kamu menyediakan kebutuhan bagi hidupmu itu, entah makanan entah pakaian, apa yang hendak kamu makan atau apa yang hendak kamu pakai. Ini adalah peringatan yang sangat ditekanakan-Nya (Mat.6:25 dst). Dan alasan yang digunakan di sini sebagian besar sama, yang dibuat untuk mendorong kita agar menyerahkan segala kekhawatiran kita kepada Allah, dan inilah cara yang benar untuk menyenangkan hati kita dalam masalah ini." 38

Dari pernyataan diatas menjelaskan bahwa orang yang kuatir tentang hidupnya adalah orang yang kurang mempercayai pemeliharaan Tuhan. Demikianlah orang percaya kita didorong untuk menyerahkan segala kekuatiran diri kita kepada Tuhan. Tong mengatakan bahwa:

"Mungkin kamu telah berpuluh-puluh tahun menjadi orang Kristen, tetapi belum pernah belajar untuk tidak kuatir. Suatu hari seorang yang sangat kaya sedang menghitung-hitung hartanya. Selesai menghitung, dia menangis dengan berkata dalam hatinya, hartaku hanya cukup dipakai oleh anak cucuku sampai 14 generasi saja.Anak cucu sampai 14 generasi masih cukup, generasi ke-15 akan jadi pengemis". 39

Ternyata di dalam kehidupan orang Kristen yang sudah bertahun-tahun percaya kepada Yesus Kristus masih saja kuatir akan masa depan anak dan cucunya. Bukan hanya non-kristen saja yang kuatir akan hidupnya, tetapi orang

${ }^{37}$ Dianner Bargent, Tafsiran Alkitab Perjanjian Baru,(Yogyakarta : lembaga Biblika Indonesia, 2015), 44.

${ }^{38}$ Matthew Henry,Injil Lukas 1-12, (Surabaya : Momentum Christian Literarure, 2009), 455.

${ }^{39}$ Stephen Tong.., 146. 
Kristen pun yang sudah menerima Kristus sebagai juruselamat masih saja kuatir akan hidupnya.

Oleh karena itu, betapa berhikmatnya statement Tuhan Yesus ketika Ia mengatakan jangan sekali-kali hidupmu khawatir apa yang kalian makan dan minum. Ia melanjutkan lagi dengan kata-kata yang menghibur, "sebab Bapa di sorga Ia mengetahui apa yang kita perlukan, tetapi yang paling ditekankan-Nya disini ialah carilah dahulu kerajaan Allah dan kebenaran-Nya (Mat. 6:33).

Karena kekuatiran tidak pernah menolong bahkan merusak hubungan kita dengan Tuhan. ${ }^{40}$ Perlu kita menyadari bahwa Tuhan mampu menolong umatNya.sebaliknya, kekuatiran semacam itu tidak patut bagi seorang yang beriman kepada Tuhan. Jadi, sebagai orang beriman perlu belajar untuk menerima apa yang terjadi pada dirinya. ${ }^{41}$ Rasul Petrus berkata serahkanlah segalanya kekuatiranmu bagi Tuhan, maka Ia akan memelihara engkau (1Pet. 5:7), artinya Ia akan berikan apa yang kaubutuhkan sehubungan dengan kebutuhan pokok (Kej. $45: 11 ; 50: 21){ }^{42}$ Inlah cara mengatasi kekuatiran dengan menunjukkan jalan untuk menang atas ketakutan. Mencari kerajaan Allah dan kebenaran-Nya tanpa mengenal lelah merupakan penangkal terhadap roh kekuatiran dalam diri kita dan menjadi jaminan bahwa Tuhan Allah akan menyediakan apa yang kita perlukan. Artinya mempercayai dan meyakini kemampuan Allah untuk memenuhi kebutuhan kita merupakan sasaran utama dari kehidupan yang bebas dari kekuatiran. Filipi 4:9 mengatakan, Allahku akan memenuhi segala keperluanmu menurut kekayaan dan kemuliaan-Nya dalam Kristus Yesus. Ayat ini sungguh menggembirakan dan sungguh luar biasa.Itu menunjukkan bahwa sumber segala kebutuhan kita adalah Allah. ${ }^{43}$

Berdasarkan paparan di atas penulis menyimpulkan orang yang kuatir adalah orang yang melenceng dari ajaran Tuhan Yesus atau tidak mengutamakan kerajaan Allah.

\footnotetext{
${ }^{40}$ Stepon Tong,Pengudusan emosi...,155

${ }^{41}$ Hudson T. Armerding, Pola Hidup Orang Kristen, (Malang : Gandum Mas, 1989), 376

${ }^{42}$ M.C. Barth, Tafsiran Alkitab Mazmur 42-89,(Jakarta: BPK Gunung Mulia, 1993), 90

${ }^{43}$ David T. Moore, Kuatir Pedoman Bagi Konselor..., 163
} 
Berdasarkan paparan di atas penulis menyimpulkan serahkanlah pemeliharaan hidupmu pada Tuhan baik dalam kebutuhan supaya dirimu menang melawan kekuatiranmu dalam imanmu kepada-Nya dengan tujuan memuliakan Dia.

\section{Rangkuman}

Kekuatiran merupakan masalah yang serius di dalam kehidupan manusia. Sehingga kekuatiran itu bisa melumpuhkan jiwa manusia atau tidak memberikan perasaan yang semangat untuk melakukan sesuatu yang harus dikerjakan. Di sebabkan karena kekuatiran ini memiliki strategi yang merusak hubungan kita dengan Tuhan. Misalnya merasa takut, cemas, gelisah dan panik. Jadi, mengapa ada kekuatiran itu di dalam kehidupan manusia, karena kurang beriman atau kurang mempercayai pemeliharaan Tuhan. Sehingga kekuatiran itu merupakan penyangkalan diri manusia dan ketidakpercayaan manusia secara terang-terangan bahwa Allah tidak mampu atau tidak ingin menepati janji-Nya kepada kita. Sehingga kekuatiran itu bisa mengakibatkan atau merusak hubungan kita dengan Tuhan. Seperti yang telah dikatakan oleh Tuhan Yesus dalam perumpamaan tersebut bahwa kekhwatiran itu dapat menghimpit dan membunuh roh kita. Jadi, apa yang harus kita lakukan sebagai orang percaya untuk menghindari atau mengatasi hal kekuatiran dalam kehidupan kita sebagai pengikut Kristus yaitu mempercayai dan meyakini kemampuan atau kesanggupan Allah untuk memenuhi kebutuhan kita. Ini merupakan sasaran utama dari kehidupan kita untuk membebaskan diri dari kekuatiran. 


\section{DAFTAR PUSTAKA}

.... (1974). Alkitab, Jakarta: Lembaga Alkitab Indonesia

Abineno, J.L. Ch. (2009). Khotbah Di Bukit catatan-catatan tentang Matius 5-7, Jakarta: BPK Gunung Mulia.

Ali, Lukman. (1994). Kamus Besar bahasa Indonesia Edisi Kedua, Jakarta: Balai Pustaka.

Arichea, Daniel. (2013). Surat Pertama Petrus,Jakarta: Lembaga Alkitab Indonesia.

Barclay, William. (2003). Pemahaman Alkitab setiap hari Injil Matius 1-10, Jakarta: PT BPK Gunung Mulia

Bargent, Dianner. (2015). Tafsiran Alkitab Perjanjian Baru, Yogyakarta: Lembaga Biblika Indonesia.

Barth, M.C. (1993). Tafsiran Alkitab Mazmur 42-89, Jakarta: BPK Gunung Mulia.

Beck, James R. (2001). Bimbingan Praktis mengatasi Kekuatiran,Jakarta: BPK Gunung Mulia.

Brill, Wesley. (2003). Tafsiran Surat Filipi,Bandung: Yayasan Kalam Hidup.

Browning, W.R.F. (2011). Kamus Alkitab, Jakarta: BPK Gunung Mulia.

C. Stine, Philip. (2008). Injil Matius,Jakarta : Lembaga Alkitab Indonesia

Champion, Deni J. (1999). Metode dan Masalah Penelitian Sosial, Bandung: Rafika Aditama.

Chapman, Adima (2014). Pengantar Perjanjian Baru, Bandung: Sahabat Kalam Hidup II.

Dharmaputra, T.S. (2006). Prinsip-Prinsip Teologi,Jakarta: Yayasan Pelayanan Kawan Sejati.

E. Alister, Mcgrath. (1996). The Niv Thematic Study Bible Holdder \& Stoughton: London Sydey Auckland.

Edwin dan Hardius, Mustava. (2008). Proses Penelitian Kualitatif,Jakarta: Lembaga Penerbit FEUI.

Ellis, E. (1995). Ensiklopedi Alkitab Masa Kini jilid 1 A-L,Jakarta: Yayasan Komunikasi Bina Kasih/OMF. 
Ferguson, Sinclai, B. (2002). Hati Yang Diprsembahkan Kepada Allah,Surabaya : Momentum Christian Literature

Hadiwijoyo, Harun. (2013). Tafsiran Alkitab Masa Kini,Jakarta: Yayasan komunikasi Bina Kasih.

Heer, J.J. de. (2011). Injil Matius Jakarta: BPK Gunung Mulia Drewes. (2012). Satu Injil Tiga Pekabar,Jakarta : Gunung Mulia.

Henry,Matthew. (2013). Kitab Amsal Surabaya: Momentum Cristian Literature

Hepper ,F. N. (1995). Ensiklopedi Alkitab Masa Kini jilid 1 A-L,Jakarta: Yayasan Komunikasi Bina Kasih/OMF.

Hiskin, Richard, W. (2010). Pengantar Perjanjian Baru Pendekatan kritis Terhadap masalah-masalahnya,Jakarta: BPK Gunung Mulia.

Indra, Ichwei, G. (2003). Teologi Sistematis Pengetahuan Lanjutan Bagi Kaum Awam dan Anggota Gereja,Bandung: Yayasan Baptis Indonesia.

Lumintang, Stevri Indra. (2015). Theologi Kepemimpinan Kristen, Jakarta: Geneva Insani Indonesia.

Martasudjita, E. (2000). Inspirasi Batin Renungan Sepanjang Tahun 1, Yogyakarta :Kanisus anggota IKAPI.

Moeliono, Anton, M. (1991). Kamus Besar Bahasa Indonesia,Jakarta: Balai Pustaka.

Monny. (2006). Selalu Ingat Membaca Alkitab,Jakarta: Sinondang Media.

Moore, David, T. (2011). Kuatir Pedoman Bagi Konselor, Jakarta: BPK Gunung Mulia.

Packer, J.I. (2004). God's Plans For You,Surabaya : Momentum Christian Literature.

Pasaribu, Marulak. (2005). Eksposisi Injil Sinoptik,Malang: Gandum Mas

Paterson, Rober,t M. (2009). Kitab Keluaran, Jakarta: BPK Gunung Mulia.

Pfeiffer, Charles, F. (2001). The Wycliffe Bible Commentary Tafsiran Alkitab Volumen 1Perjanjian Lama, Malang: Gandum Mas.

Poerwa, darminta. (1976). Kamus Umum Bahasa Indonesia, Jakarta: panitia Pembangunan Bahasa Indonesia. 
Prime, Derek. (2006). Tanya Jawab tentang Iman Kristen, Jakarta: Yayasan Komunikasi Bina Kasih/OMF.

Rahadi, Christian Nur. (2008). Umat Perjanjian Baru,Bandung: Revival Publising House.

Rungkat, Jimmy. (2010). Theologi Politik Yesus, Batu Malang: Depatermen Literatur Multimedia.

Sosipater, Karel. (2011). Etika Taman Eden, Jakarta: Suara harapan Bangsa.

Stassen, Glen, H. (2008). Etika kerajaan mengikuti Yesus dalam masa kini, Surabaya : Momentum.

Strong, James. (1979). The Exhaustive Concordance Of The Bible Greek Dictonary Of The New Tastament, Lowa: World Bible Publising

Subeno, Sutjipto. (2004). Pergumulan Mengerti Kehendak Allah Tafsiran kitab Habakuk, Surabaya: Momentum

Sugono, Dendy. (2011). Kamus Besar Bahasa Indoneia, Jakarta: Gramedi Pustaka Utama.

Sularso. (1995). Ensklopedi Alkitab masa Kini,Jakarta: Yayasan Komunikasi Bina Kasih.

Tenney, M.C. (1992). Survei Perjanjian Baru,Malang: Gandum Mas.

Tong,Joseph. (2002). Teologi Abu-Abu Pluralisme Iman, Malang: Persekutuan Literatur Kristen Indonesia.

Tong,Stephen. (2003). Aristek Jiwa,Surabaya: Momentum.

Tulluan, Ola. (1999). Introduksi Perjanjian Baru, Malang: Yayasan Persekutuan.

Walvoord, John F. (2006). Buku Alkitab Penuntun, Jakarta: Lembaga Alkitab Indonesia

Wang, Andri. (2011). Rahasia Tiongkok Kuno Untuk Sehat Bahagia dan Panjang

Wiersbe, Warren, W. (2012). Loyal Di dalam Kristus Mengikut Raja segala Raja, Bandung: Yayasan Kalam Hidup.

Wirnano, Surakhman. (2004).Pengantar Penelitian Ilmu Dasar Metode Tehknik, Bandung : Yayasan Kalam Hidup.

Wiseman, D.J. (1995). Ensiklopedi Alkitab Masa Kini, Jakarta: Yayasan Komunikasi Bina Kasih/OMF. 
Wongso, Peter. (1989). Hermeneutika Eskatolog, Malang: Seminar Alkitab Asia Tenggara.

(1989). Hermeneutika Eskatolog, Malang: Seminar Alkitab Asia Tenggara.

Yan, Antony. (2014). Teologi Prjanjian Baru, Bandung: Kalam Hidup, Pekabaran Injil Indonesia YPPII. 